\title{
ANALISIS FAKTOR YANG MEMPENGARUHI PENERAPAN INISIASI MENYUSU DINI (IMD) DI WILAYAH KERJA PUSKESMAS JUMPANDANG BARU MAKASSAR
}

\section{ANALYSIS OF THE FACTORS AFFECTING THE IMPLEMENTATION OF INITIATED BREASTFEEDING (IMD) IN THE WORKING AREA OF JUMPANDANG BARU PUSKESMAS MAKASSAR}

\author{
Nurjaya, Djuhadiah Saadong, Subriah \\ Jurusan Kebidanan Makassar Poltekkes Kemenkes Makassar
}

\begin{abstract}
ABSTRAK
Latar Belakang : Inisiasu Menyusu Dini (IMD) sangat bermanfaat bukan hanya bagi bayi yang baru lahir tetapi juga bagi ibu yang melakukan IMD. Jika bayi berada dalam dekapan ibu, maka bayi tersebut dengan sendirinya merangkak ke payudara ibu dan akan mulai menghisap puting susu ibunya. Data menunjukkan bahwa di Indonesia, persentase pemberian Air Susu lbu (ASI) dalam 1 jam pertama setelah bayi dilahirkan masih rendah yaitu sebesar $38 \%$. Angka tersebut masih jauh tertinggal bila dibandingkan dengan negara-negara berkembang lainnya seperti Oman $(85 \%)$, Srilangka (75\%), Filipina (54\%), dan Turki $(54 \%)$ (SDKI 2017). Oleh karena itu tujuan dari penelitian ini adalah untuk Mengetahui faktor yang mempengaruhi penerapan inisiasi menyusu dini di wilayah kerja Puskesmas Jumpandang Baru Makassar tahun 2018. Jenis penelitian ini: Penelitian ini menggunakan desain case control study. Populasi pada penelitian ini adalah semua ibu yang melahirkan di Wilayah kerja Puskesmas Jumpandang Baru. Pengambilan sampel dilakukan dengan Consecutive Sampling yaitu dengan perbandingan $1: 2$ yang dibutuhkan adalah 30 kasus dan 60 kontrol.. Pengumpulan data dilakukan menggunakan lembaran kuesioner. Data dianalisis secara univariat, bivariat dan multivariat dengan menggunakan uji Regresi Berganda Logistik. Hasil penelitian : Ada pengaruh pengetahuan ( OR = $5,5)$, peran bidan/penolong persalinan $(\mathrm{OR}=12,571)$, dukungan dari suami $(\mathrm{OR}=3,3$ ) terhadap penerapan inisiasi menyusu dini dan Hasil uji multivariat menunjukkan bahwa variabel peran bidan/penolong persalinan merupakan faktor yang paling berpengaruh terhadap penerapan inisiasi menyusu dini dengan nilai Wald sebesar 13 dan signifikansi sebesar 0,010. Kesimpulan : Terdapat pengaruh pengetahuan, peran bidan/penolong persalinan , dukungan dari suami terhadap penerapan inisiasi menyusu dini, dan variable peran bidan/penolong persalinan yang paling berpengaruh terhadap penerapan inisiasi menyusu dini.
\end{abstract}

Kata Kunci: Air Susu Ibu (ASI), Insisiasi Menyusu Dini (IMD), Penerapan

\section{ABSTRACT}

Background: IMD is very beneficial not only for newborns but also for mothers who do IMD. If the baby is in the mother's arms, the baby naturally crawls into the mother's breast and will start sucking her mother's nipples. Data shows that in Indonesia, the percentage of breastfeeding in the first 1 hour after the baby is born is still low at 38\%. This figure is far behind when compared to other developing countries such as Oman (85\%), Sri Lanka (75\%), the Philippines (54\%), and Turkey (54\%) (IDHS 2017). Therefore the purpose of the research This is to find out the factors that influence the application of early breastfeeding initiation in the working area of the Jumpandang Baru Makassar Health Center in 2018. Type of research: This study uses a case control study design. The population in this study were all mothers who gave birth in the Working Area of the Jumpandang Baru Health Center. Sampling was done by Consecutive Sampling, which is a ratio of 1:2. It takes 30 cases and 60 controls. Data collection is done using a questionnaire sheet. Data were analyzed by univariate, bivariate and multivariate using the Multiple Logistic Regression test. Results: There was influence of knowledge $(O R=5,5)$, role of midwife / birth attendant $(O R=13)$, support from husband $(O R=3,3)$ on the application of early breastfeeding initiation and multivariate test results showed that the role of midwives / birth attendants was a factor the most influential on the application of early breastfeeding initiation with a Wald value of 12,956 and a significance of 0.010. Conclusion: There is an influence of knowledge, the role of midwives / birth attendants, support from husbands on the application of early breastfeeding initiation, and the role variables of midwives / birth attendants who most influence the application of early breastfeeding initiation.

Keywords: Breast Feeding, Early Breastfeeding Initiation, Application

\section{PENDAHULUAN}

Inisiasi Menyusu Dini adalah proses bayi menyusu segera setelah dilahirkan dimana bayi dibiarkan menyusu sendiri tanpa dibantu orang lain. Bayi dipotong tali pusarnya, diletakkan di dada ibu dan kemudian dibiarkan mencari puting susu ibunya sendiri dalam waktu satu jam pertama kehidupan. Pada IMD bayi tidak boleh dipisahkan terlebih dahulu dari ibu.
Hal ini karena kontak kulit antara ibu dan bayi yang terjadi pada IMD mempunyai manfaat antara lain untuk meningkatkan reflek bayi dalam menyusui sehingga bayi bisa menyusu sendiri, menjaga agar bayi tetap hangat, dan membuat bayi tenang dan tidak menangis. Selain itu, manfaat IMD yang didapat dari proses menyusui bayi antara lain adalah dapat mencegah kematian yang disebabkan oleh sepsis, 
diare, dan pneumonia dan dapat membantu pertumbuhan dan perkembangan bayi.

IMD sangat bermanfaat bukan hanya bagi bayi yang baru lahir tetapi juga bagi ibu yang melakukan IMD. Jika bayi berada dalam dekapan ibu, maka bayi tersebut dengan sendirinya merangkak ke payudara ibu dan akan mulai menghisap puting susu ibunya. Hal ini akan merangsang pelepasan okstitosin yang akan menyebabkan terjadi kontraksi otot rahim sehingga perdarahan sesudah melahirkan dapat berhenti lebih cepat dan akan lebih cepat mengembalikan ukuran rahim seperti semula. IMD juga dapat membantu ibu untuk memproduksi ASI yang cukup yang dibutuhkan bayi selama hidupnya (Ambarwani. 2011).

Sampai saat ini, masih terdapat banyak kasus dimana bayi lahir tidak secara langsung diberikan kepada ibunya untuk dilakukan kontak kulit ke kulit agar segera melakukan proses menyusu, hal ini dapat berdampak pada menurunnya kualitas sumber daya manusia Indonesia pada generasi akan datang seperti malnutrisi, kelemahan, sampai pada IQ point yang rendah. Malnutrisi merupakan pemicu kematian pada bayi (Elza, 2018).

Data menunjukkan bahwa di Indonesia, persentase pemberian Air Susu Ibu (ASI) dalam 1 jam pertama setelah bayi dilahirkan masih rendah yaitu sebesar $38 \%$. Angka tersebut masih jauh tertinggal bila dibandingkan dengan negara-negara berkembang lainnya seperti Oman (85\%), Srilangka (75\%), Filipina (54\%), dan Turki (54\%)(SDKI 2017), Menurut Survey Demografi Kesehatan Indonesia (SDKI) 2017, IMD di Indonesia hanya sebesar $3.7 \%$. Di Indonesia saat ini angka kematian bayi masih sangat tinggi yaitu 35 tiap 1.000 kelahiran hidup, itu artinya dalam satu tahun sekitar 175.000 bayi meninggal sebelum mencapai usia satu tahun. Angka kematian Balita Indonesia (The Word Health Report 2015) adalah 46/1000 kelahiran hidup 430 balita meninggal / hari setiap hari yang berarti terdapat 1 balita meninggal setiap 2 $1 / 2$ menit (SDKI 2017, Calverton, Marylan, USA: BPS and Macro International2017).

Berdasarkan data Dinas Kesehatan Provinsi Sulawesi Selatan, angka kematian bayi di Sulawesi Selatan mencapai 36 dari 1.000 kelahiran bayi hidup. Menurut Kasubdin Kesehatan Keluarga Dinkes Provinsi Sulawesi Selatan, 40\% dari angka kematian bayi di Provinsi Sulawesi Selatan akibat kekurangan gizi, dengan rentang usia
1-8 hari kelahiran. Oleh karena itu, pemberian ASI, terutama inisiasi menyusu secara dini sangat penting bagi bayi. Selain melatih insting, juga membentuk kekebalan tubuhnya lebih cepat (Dinas Kesehatan Provinsi Sulawesi Selatan, 2017)

Banyak aspek yang mempengaruhi pelaksanaan praktek IMD antara lain adalah ibu menyusui menghadapi banyak hambatan yang berhubungan dengan pelayanan yang diperoleh di tempat persalinan, dukungan yang diberikan oleh anggota keluarga di rumah, banyaknya ibu yang belum dibekali pengetahuan yang cukup tentang manajemen laktasi, pengaruh budaya dan norma yang berkembang di kalangan anggota keluarga, rekan dan masyarakat secara umum dan pencegahan terjadinya hipotermi pada bayi. Masalah utama rendahnya pemberian ASI di Indonesia adalah faktor sosial budaya, kurangnya pengetahuan akanpentingnya ASI serta gencarnya promosi susu formula (Virarisca S, dkk. 2010).

Menurut data dari hasil penelitian yang dilakukan oleh Ida Diana (2016) di RSIB Bunda Makassar diperoleh data 5 dari 8 orang ibu bersalin yang tidak melakukan inisiasi menyusu dini, bayinya mengalami hipotermi dengan suhu $35^{\circ} \mathrm{C}$ sedangkan 3 ibu bersalin yang melakukan inisiasi menyusu dini bayinya tidak mengalami hipotermia dengan rata-rata suhu $36,5^{\circ} \mathrm{C}$.

Menciptakan kebiasaan pemberian ASI yang baik sejak menit pertama bayi baru lahir sangat penting untuk kesehatan bayi dan keberhasilan pemberian ASI itu sendiri, menyusui yang paling mudah dan sukses dilakukan adalah bila ibu sendiri sudah siap fisik dan mentalnya untuk melahirkan dan menyusui, serta bila ibu mendapat informasi, dukungan, dan merasa yakin akan kemampuannya untuk merawat bayinya sendiri. Keberhasilan program IMD juga sangat dipengaruhi oleh sikap pengetahuan dan peran bidan/dokter penolong persalinan itu sendiri (Aprillia Y, 2017).

Berdasarkan penelitian Ngatimin, dkk. di Kota Parepare tahun 2017, mengatakan bahwa orang lain yang berperan dalam membantu ibu memutuskan untuk melakukan inisiasi menyusu dini, tidak selalu anggota keluarga. Peran suami lebih banyak memberikan kebebasan dan mendukung pilihan istri. Dukungan suami antara lain dapat terlihat pada sikapnya yang pengertian dan tidak membebani 
istrinya dengan pekerjaan rumah tangga saat tiba waktu menyusui. Terkait dengan praktek IMD, peran suami lebih pasif dan menyerahkan sepenuhnya keputusan kepada istrinya.

Tujuan Penelitian ini adalah untuk Mengetahui faktor yang mempengaruhi penerapan inisiasi menyusu dini di wilayah kerja Puskesmas Jumpandang Baru Makassar tahun 2019.

\section{METODE}

Penelitian ini menggunakan desain case control study yaitu rancangan studi epidemiologi yang mempelajari hubungan antara paparan (faktor penelitian) dan penyakit dengan cara membandingkan kelompok kasus dengan kelompok kontrol berdasarkan status paparanya. Variabel independen adalah pengetahuan, peran bidan / penolong persalinan, dukungan suami, sedangkan variabel dependennya adalah penerapan inisiasi menyusu dini (IMD). Penelitian ini dilaksanakan di wilayah kerja Puskesmas Jumpandang Baru Kota Makassar Propinsi Sulawesi Selatan pada Bulan Maret s.d. Agustus 2019.

Populasi dalam penelitian ini adalah semua ibu yang melahirkan di Wilayah kerja Puskesmas Jumpandang Baru Kota Makassar, Besar sampel diambil dengan rumus studi kasus kontrol untuk pengujian hipotesis terhadap Odds Ratio (Lameshow, 1990), Dengan besaran sampel yang didapatkan sebanyak 30 orang, maka besar sampel minimal dengan perbandingan $1: 2$ yang dibutuhkan adalah 30 kasus dan 60 kontrol. Sampel diambil dengan menggunakan teknik Consecutive Sampling yaitu pengambilan sampel yang sesuai kriteria sampai kurun waktu tertentu. Analisa data dilakukan untuk mempermudah interpretasi dan menguji hipotesis penelitian tersebut dengan menggunakan Analisis univariat dan Analisis bivariat.

Pengumpulan data terhadap responden dilakukan dengan menggunakan lembar kuesioner terstruktur untuk mendapatkan informasi tentang faktor yang mempengaruhi penerapan inisiasi menyusu dini di Puskesmas Jumpandang Baru di Kecamatan Tallo Kota Makassar. Data yang diperoleh kemudian diolah dengan menggunakan computer program SPSS dan disajikan dalam bentuk tabel frekuensi dan crosstab (tabulasi silang).
HASIL

1. Karakteristik Umum Responden

Distribusi responden berdasarkan umur, persentase tertinggi berada pada kelompok umur 20-35 Tahun yaitu sebanyak 71 orang $(78,9 \%)$ sedangkan persentase terendah berada pada kelompok umur $<20$ Tahun yaitu sebanyak 7 orang $(7,8 \%)$, distribusi responden berdasarkan tingkat pendidikan dengan persentase tertinggi berada pada tingkat pendidikan SMA yaitu sebanyak 34 orang $(45,0 \%)$ sedangkan persentase terendah berada tingkat pendidikan PT yaitu 10 orang $(11, \%)$.

$$
\text { Pada distribusi responden }
$$
berdasarkan pekerjaan dengan persentase tertinggi berada pada ibu yang bekerja sebagai Ibu Rumah Tangga yaitu sebanyak 88 orang $(97,8 \%) \quad$ sedangkan persentase terendah pada ibu yang bekerja sebagai wiraswasta dan PNS yaitu hanya 1 orang $(1,1 \%)$, distribusi responden berdasarkan paritas dengan persentase tertinggi berada pada ibu multipara (2-4 anak) yaitu sebanyak 65 orang $(72,2 \%)$ sedangkan persentase terendah pada ibu grand multipara yaitu hanya 11 orang $(12,2 \%)$.

\section{Analisis Univariat}

Analisis univariat dalam penelitian ini yaitu faktor yang mempengaruhi penerapan inisiasi menyusu dini di wilayah kerja Puskesmas Jumpandang Baru Kec.Tallo kota Makassar. Berikut distribusi responden berdasarkan pengetahuan, peran bidan, dan dukungan suami di wilayah kerja Puskesmas Jumpandang Baru Kecamatan Tallo Kota Makassar tahun 2019 menunjukkan bahwa responden yang memiliki pengetahuan yang cukup yaitu sebanyak 48 orang $(53,3 \%)$ sedangkan responden yang memiliki pengetahuan kurang yaitu sebanyak 42 orang (46,7\%).

Pada responden yang mendapat dukungan dari bidan sebagai penolong persalinan yaitu sebanyak 69 orang $(76,7 \%)$ sedangkan responden yang tidak mendapat dukungan dari bidan yaitu hanya 21 orang $(23,3 \%)$, responden yang tidak mendapat dukungan dari suami dalam memotivasi ibu untuk melaksanakan Inisiasi 
Menyusu Dini (IMD) yaitu sebanyak 46 orang $(51,1 \%)$ sedangkan responden yang mendapat dukungan dari suami yaitu 44 orang $(48,9 \%)$, dan responden yang menyusui $\leq 1$ jam pertama kelahiran yaitu sebanyak 60 orang $(66,7 \%)$ sedangkan responden yang tidak menyusui $\leq 1$ jam pertama kelahiran yaitu hanya 30 orang $(57,3 \%)$.

\section{Hasil Analisis Bivariat}

a. Untuk mengetahui pengaruh pengetahuan terhadap penerapan inisiasi menyusu dini.

Pengaruh pengetahuan terhadap penerapan inisiasi menyusu dini di wilayah kerja Puskesmas Jumpandang Baru Kecamatan Tallo Kota Makassar tahun 2019 menunjukkan bahwa responden yang memiliki pengetahuan yang kurang cenderung tidak melakukan IMD di wilayah kerja Puskesmas Jumpandang Baru Kecamatan Tallo Kota Makassar sebanyak 22 orang $(73,3 \%)$, lebih tinggi dari responden yang memiliki pengetahuan cukup sebanyak 8 orang $(26,7 \%)$. Sedangkan responden yang memiliki pengetahuan cukup cenderung melaksanakan IMD sebanyak 40 orang $(66,7 \%)$.

Berdasarkan hasil analisis Odds Ratio (OR) terhadap pengetahuan responden didapatkan OR sebesar 5,500 pada tingkat kepercayaan $(\mathrm{Cl})=95 \%$ dengan lower limit $=2,083$ dan upper limit $=14,524$. Oleh karena nilai lower limit dan upper limit tidak mencakup nilai satu, maka nilai 5,5 dianggap berpengaruh antara pengetahuan terhadap penerapan inisiasi menyusu dini (IMD). Dengan demikian, responden yang memiliki pengetahuan yang cukup berpengaruh 5,5 kali lebih besar untuk melaksanakan IMD dibandingkan dengan responden yang memiliki pengetahuan kurang, atau dapat disimpulkan bahwa pengetahuan merupakan faktor pengaruh penerapan inisiasi menyusu dini (IMD).

b. Untuk mengetahui pengaruh peran bidan / penolong persalinan terhadap penerapan inisiasi menyusu dini.

Pengaruh peran bidan/ penolong persalinan terhadap penerapan inisiasi menyusu dini di wilayah kerja Puskesmas Jumpandang Baru Kecamatan Tallo Kota Makassar menunjukkan bahwa responden yang tidak mendapat dukungan dari bidan cenderung tidak melakukan IMD di wilayah kerja Puskesmas Jumpandang Baru Kecamatan Tallo Kota Makassar sebanyak 16 orang $(53,3 \%)$, lebih tinggi dari responden yang mendapat dukungan dari bidan hanya 14 orang (46,7\%). Sedangkan responden yang mendapat dukungan dari bidan sebagai penolon persalinan cenderung melaksanakan IMD sebanyak 55 orang (76,7\%).

Berdasarkan hasil analisis Odds Ratio (OR) terhadap peran bidan/ penolong persalinan didapatkan OR sebesar 12,6 pada tingkat kepercayaan $(\mathrm{Cl})=95 \%$ dengan lower limit $=3,929$ dan upper limit $=40,223$. Oleh karena nilai lower limit dan upper limit tidak mencakup nilai satu, maka nilai 12,571 dianggap berpengaruh antara peran bidan/ penolong persalinan terhadap penerapan inisiasi menyusu dini (IMD). Dengan demikian, responden yang mendapatkan dukungan bidan/ penolong persalinan berpengaruh 12,6 kali lebih besar untuk melaksanakan IMD dibandingkan dengan responden yang tidak mendapatkan dukungan bidan, atau dapat disimpulkan bahwa peran bidan/ penolong persalinan merupakan faktor pengaruh penerapan inisiasi menyusu dini (IMD).

c. Untuk mengetahui pengaruh dukungan suami terhadap penerapan inisiasi menyusu dini.

Pengaruh dukungan suami terhadap penerapan inisiasi menyusu dini di wilayah kerja Puskesmas Jumpandang Baru Kecamatan Tallo Kota Makassar tahun 2019 menunjukkan bahwa responden yang tidak mendapat dukungan dari suami dalam 
memotivasi ibu untuk melaksanakan IMD cenderung tidak melakukan IMD di wilayah kerja Puskesmas Jumpandang Baru Kecamatan Tallo Kota Makassar sebanyak 21 orang $(70,0 \%)$, lebih tinggi dari responden yang mendapat dukungan dari suami hanya 9 orang $(30,0 \%)$. Sedangkan responden yang mendapat dukungan suami cenderung melaksanakan IMD sebanyak 35 orang (58,3\%).

Berdasarkan hasil analisis Odds Ratio (OR) terhadap dukungan suami didapatkan OR sebesar 3,3 pada tingkat kepercayaan $(\mathrm{Cl})=95 \%$ dengan lower limit $=1,283$ dan upper limit = 8,316 . Oleh karena nilai lower limit dan upper limit tidak mencakup nilai satu, maka nilai 3,3 dianggap berpengaruh antara dukungan suami terhadap penerapan inisiasi menyusu dini (IMD). Dengan demikian, responden yang mendapatkan dukungan suami berpengaruh 3,3 kali lebih besar untuk melaksanakan IMD dibandingkan dengan responden yang tidak mendapatkan dukungan suami, atau dapat disimpulkan bahwa dukungan suami merupakan faktor pengaruh penerapan inisiasi menyusu dini (IMD).

\section{Penentuan Variabel Independen yang akan Diikutkan Dalam Uji Regresi Berganda Logistik \\ Variabel yang diduga} merupakan faktor pengaruh penerapan inisiasi menyusu dini (IMD) akan dijadikan calon uji multivariat. Variabel yang akan diikutkan adalah variabel yang mempunyai nilai $p<0,25$. Ketentuan nilai $p<0,25$ adalah memberi peluang variabel independen yang mungkin secara bersamaan memberikan pengaruh yang bermakna terhadap variabel dependen. Dari hasil uji bivariat tentang hubungan variabel independen dengan variabel dependen atau variabel yang secara subtantif diduga ada hubungan yang erat dengan nilai $p$ dari semua variabel bebas, menunjukkan bahwa dari 3 variabel yang diteliti semua variabel memenuhi syarat untuk diikutkan dalam analisis multivariat dengan nilai $p<0,25$, yaitu pengetahuan, Peran Bidan / Penolong Persalinan dan dukunga suami sehingga variabel tersebut dapat dimasukkan dalam analisis multivariat dengan uji regresi berganda logistik.

\section{Hasil Analisis Multivariat}

Analisis multivariat yang digunakan dalam penelitian ini adalah analisis regresi berganda logistik karena variabel terikat merupakan variabel dikotomi dengan tujuan untuk melihat besar risiko masing-masing variabel bebas dengan variabel terikat.

Tujuan analisis ini adalah untuk mengetahui besarnya OR murni dari variabel bebas, setelah memperhitungkan variabel lain. Keluaran dari analisis ini adalah nilai Odds Ratio murni yang sudah dikontrol dengan menghilangkan pengaruh variabel yang diduga sebagai perancu dan memperhitungkan adanya interaksi antara variabel lain dengan variabel bebas utama. Variabel yang dilakukan saat uji memiliki $p<0,25$ dapat dijadikan kandidat yang akan dimasukkan dalam model multivariat. Untuk melihat variabel yang sesungguhnya berpengaruh terhadap penerapan inisiasi menyusu dini (IMD) menunjukkan bahwa variabel peran bidan / penolong persalinan merupakan faktor yang paling berpengaruh terhadap penerapan Inisiasi Menyusu Dini (IMD) dengan nilai Wald sebesar 12,956 dan signifikansi sebesar 0,010. Dengan demikian, peran bidan / penolong persalinan merupakan faktor yang paling berpengaruh (dominan) terhadap penerapan Inisiasi Menyusu Dini (IMD) di wilayah kerja Puskesmas Jumpandang Baru Kecamatan Tallo Kota Makassar tahun 2019.

\section{PEMBAHASAN}

Inisiasi menyusu dini adalah proses bayi menyusu segera setelah dilahirkan 
dimana bayi dibiarkan menyusu sendiri tanpa dibantu orang lain. Bayi dipotong tali pusarnya, diletakkan di dada ibu dan kemudian dibiarkan mencari puting susu ibunya sendiri dalam waktu satu jam pertama kehidupan. Pengetahuan ibu, peran bidan, dukungan suami merupakan faktor yang dapat mempengaruhi ibu dalam penerapan Inisiasi menyusu dini. Sehingga tujuan dari penelitian ini adalah untuk mengetahui besar risiko dari faktor yang diduga erat kaitannya dengan kejadian penerapan Inisiasi menyusu dini. Untuk tujuan tersebut maka pada analisis data digunakan nilai OR (Odds Ratio) yang sejalan dengan jenis rancangan penelitian yang digunakan yaitu kasus kontrol (Retrospektif). Adapun pembahasan untuk masing-masing variabel independen berdasarkan hasil analisis data yang telah dilakukan selengkapnya sebagai berikut.

\section{Pengetahuan Ibu}

Pada satu jam pertama bayi harus disusukan pada ibunya, bukan untuk pemberian nutrisi tetapi untuk belajar menyusu atau membiasakan menghisap puting susu dan mempersiapkan ibu untuk mulai memproduksi ASI kolostrum. Kolostrum adalah susu awal yang diproduksi oleh ibu yang baru melahirkan yakni dihasilkan dalam waktu 24 jam pertama setelah melahirkan. Kolostrum sangat kaya akan antibody. Salah satu faktor yang mempengaruhi pemberian kolostrum adalah tingkat pengetahuan ibu.

Pengetahuan pada penelitian ini adalah apa yang diketahui oleh ibu yang memiliki bayi baru lahir dalam penerapan IMD meliputi tali pusar bayi dipotong, bayi diletakkan di dada ibu, bayi dibiarkan mencari puting susu ibunya sendiri dalam waktu satu jam pertama kehidupan.yang dapat menunjang keberhasilan pemberian ASI pada anak.

Tingginya Angka Kematian Bayi (AKB) di Indonesia masih menjadi salah satu masalah kesehatan di Indonesia. UNICEF mencatat bahwa pada tahun 2010, AKB di indonesia masih sangat tinggi yaitu 17 bayi setiap 1000 kelahiran hidup. Hal ini menunjukkan bahwa pelaksanaan IMD di Indonesia belum terlaksana secara optimal. (Fikawati S, Syafiq A. 2010)
Di Indonesia hanya 44\% yang mendapat ASI 1 jam pertama setelah lahir dan hanya $62 \%$ yang mendapat ASI dalam hari pertama setelah lahir. Hal ini juga menunjukkan bahwa IMD belum terlaksana dengan baik. Kegagalan IMD disebabkan oleh beberapa faktor antara lain kurangnya pengetahuan ibu mengenai pentingnya IMD. Menurut Centers for Disease Control and Prevention (CDC), masih banyak ibu yang belum mengerti bagaimana cara menyusui yang benar. $\mathrm{Hal}$ ini menunjukkan bahwa pengetahuan ibu dalam hal menyusui bayi masih rendah. U.S Preventive Service Task Force menjelaskan bahwa pengetahuan adalah faktor intervensi yang paling efektif dalam IMD. Oleh karena itu, pengetahuan ibu mengenai IMD adalah salah satu faktor yang penting dalam kesuksesan pelaksanaan IMD. (SDKI, 2017)

Tabel 4.9 menunjukkan bahwa responden yang memiliki pengetahuan yang kurang cenderung tidak melakukan IMD di wilayah kerja Puskesmas Jumpandang Baru Kecamatan Tallo Kota Makassar sebanyak 22 orang $(73,3 \%)$, lebih tinggi dari responden yang memiliki pengetahuan cukup sebanyak 8 orang $(26,7 \%)$. Berdasarkan hasil analisis Odds Ratio menunjukkan ibu yang memiliki pengetahuan yang cukup lebih berpengaruh 5,5 kali lebih besar dalam menerapkan inisiasi menyusu dini (IMD) dari pada yang pengetahuan yang kurang $(\mathrm{OR}=5,500$; $95 \% \mathrm{Cl}$ : 2,08314,524) dan secara statistik menunjukkan ada hubungan yang bermakna $(p=0,001)$. Proporsi pengetahuan yang kurang cenderung tidak melakukan IMD di wilayah kerja Puskesmas Jumpandang Baru Kecamatan Tallo Kota Makassar sebanyak 22 orang $(73,3 \%)$, lebih tinggi dari responden yang memiliki pengetahuan cukup sebanyak 8 orang $(26,7 \%)$. Sedangkan responden yang memiliki pengetahuan cukup cenderung melaksanakan IMD sebanyak 40 orang (66,7\%).

Dengan demikian, dapat disimpulkan bahwa tingkat pengetahuan memiliki pengaruh yang signifikan, yaitu semakin tinggi tingkat pengetahuan ibu tersebut kemungkinan penerapan IMD 
akan semakin besar. Hal ini dapat menjadi dasar pertimbangan dalam upaya peningkatan pengetahuan ibu. Sebaiknya ibu terus diberi paparan informasi tentang IMD sehingga angka pelaksanaan IMD akan meningkat dan angka kematian bayi akan menurun.

Hal ini sejalan dengan penelitian yang dilakukan Hidayat (2012), menunjukkan bahwa pelaksanaan IMD pada kelompok dengan tingkat pengetahuan tinggi lebih tinggi dibanding kelompok dengan tingkat pengetahuan rendah yaitu sebesar 1,6 kali dengan signifikan $(p=0,000)$. Hal ini sesuai dengan berbagai penelitian sebelumnya yang menyebutkan bahwa tingkat pengetahuan ibu berpengaruh terhadap pelaksanaan IMD sebanyak 6 responden $(17,2 \%)$ dengan pengetahuan baik, pengetahuan cukup tentang inisiasi menyusu dini sebanyak 20 orang $(57,1 \%)$ pengetahuan kurang sebanyak 9 responden $(25,7 \%)$

Tetapi dalam penelitian ini pula didapatkan bahwa beberapa ibu yang memiliki pengetahuan yang cukup tetapi tidak melaksanakan IMD sebanyak 8 orang $(26,7 \%)$ dikarenakan rata- rata ibu merasa kelelahan setelah persalinan dan sebagian ibu tidak mendapat bantuan dari petugas persalinan untuk melaksanakan Inisiasi menyusu dini (IMD).

Secara teoritis diketahui bahwa tingkat pengetahuan mempunyai kontribusi yang besar dalam merubah perilaku seseorang untuk berbuat sesuatu. Pengetahuan yang cukup tentang IMD akan memberikan pengaruh terhadap keberhasilan menyusui. Pengetahuan tentang IMD dapat diperoleh dari berbagai sumber seperti dari petugas kesehatan, dari buku-buku atau leaflet yang memuat tentang IMD.

\section{Peran bidan/penolong persalinan}

Bidan merupakan yang pertama dan utama dalam menentukkan keberhasilan pelaksanaan IMD. Karena frekuensi kontak antara ibu dan bidan lebih sering dibandingkan dengan tenaga kesehatan lainnya. Sehingga peran bidan/penolong persalinan dalam memberikan suatu informasi, konseling, serta tindakan yang nyata sangat menentukan keberhasilan pelaksanaan
IMD itu sendiri. Tindakan nyata bidan memberi kesan terhadap ibu dan keluarganya, bahwa kegiatan IMD ini benar-benar bermanfaat untuk ibu dan bayinya (Mujiati, 2015)

Apabila bidan/penolong persalinan memfasilitasi ibu untuk segera memeluk bayinya maka interaksi ibu dan bayi diharapkan segera terjadi. Dengan pelaksanaan IMD, ibu semakin percaya diri untuk tetap memberikan ASI nya sehingga tidak merasa perlu untuk memberikan makanan atau minuman kepada bayinya dan bayi akan merasa nyaman menempel pada payudara ibu dan tenang dalam pelukan ibu segera setelah lahir (Utami Roesli, 2008)

Olehnya itu, keterampilan dalam menerapkan tatalaksana IMD dengan benar memang sudah menjadi hal yang mutlak yang harus dimiliki oleh petugas kesehatan yang menolong persalinan. lbu maupun suami yang mendampingi akan mengikuti apa saja yang disarankan dan dilakukan oleh petugas kesehatan pada saat persalinan. Apabila petugas kesehatan tidak terampil dalam penerapan langkah langkah dalam IMD maka kemungkinan besar IMD akan gagal dilaksanakan pasca persalinan, selain dipengaruhi oleh pengetahuan ibu, sikap ibu serta dukungan suami. menunjukkan bahwa responden yang tidak mendapat dukungan dari bidan cenderung tidak melakukan IMD di wilayah kerja Puskesmas Jumpandang Baru Kecamatan Tallo Kota Makassar sebanyak 16 orang (53,3\%), lebih tinggi dari responden yang mendapat dukungan dari bidan hanya 14 orang $(46,7 \%)$. Hasil penelitian menunjukkan bahwa perbandingan secara proporsional, adanya dukungan dari bidan atau penolong persalinan lebih banyak ditemukan pada kelompok yang menerapkan IMD 91,7 \% dibandingkan pada kelompok yang tidak mendapat dukungan sebesar $8,3 \%$. hasil analisis Odds Ratio (OR) terhadap peran bidan/ penolong persalinan didapatkan OR sebesar 12,6 pada tingkat kepercayaan $(\mathrm{Cl})=95 \%$ dengan lower limit $=3,929$ dan upper limit $=40,223$. Dengan demikian, responden yang mendapatkan dukungan bidan/ penolong persalinan berpengaruh 12,6 kali lebih besar untuk melaksanakan 
IMD dibandingkan dengan responden yang tidak mendapatkan dukungan bidan dan secara statistik menunjukkan ada hubungan yang bermakna $(p=$ 0,000 ).

Hal inilah yang terjadi di Puskesmas Jumpandang Baru. Sebagian dari petugas kesehatan penolong persalinan memiliki keterampilan yang memadai sehingga menerapkan IMD sesuai dengan tatalaksana yang semestinya. Hal yang membuat sebagian besar responden mendapatkan dukungan petugas kesehatan.

Berdasarkan hasil uji multivariat menunjukkan bahwa variabel peran bidan/penolong persalinan merupakan faktor yang paling berpengaruh terhadap penerapan Inisiasi menyusu dini (IMD) di Puskesmas Jumpandang Baru Kota Makassar dengan nilai Wald sebesar 13 dan signifikansi sebesar 0,000 .

Berdasarkan teori, bidan/penolong persalinan mempunyai peranan yang besar untuk mempengaruhi ibu untuk menyusui banyinya dengan baik dan benar karena penolong persalinan berperan dalam hal detik-detik/ saat kritis dimana informasi dan dukunga menyusui akan sangat mempengaruhi keputusan ibu untuk memberikan ASI pada bayinya. Penelitian ini sejalan denga penelitian Fikawati dan Syafiq (2010) dibutuhkan penolong persalinan yang dapat memfasilitasi agar bayi dapat menyusui segera dalam waktu satu jam setelah persalinan.

Hasil penelitian ini menunjukkan bahwa bidan/penolong persalinan memiliki peranan dalam menginformasikan dan berperan dalam menggerakkan praktek inisiasi menyusu dini pada ibu. jika penolong persalinan melakukan inisiasi pada ibu, maka praktek IMD akan terlaksana begitu juga sebaliknya.

Sesuai dengan penelitian yang dilakukan oleh Sheilla, Djaswadi, dan Sulchan (2015) menunjukkan bahwa dukungan tenaga kesehatan mempunyai hubungan yang signifikan dengan keberhasilan pelaksanaan IMD dengan nilai $p=0,002$ dengan persentase ibu yang mendapatkan dukungan bidan dalam penerapan IMD sebanyak 32 orang $(65,6 \%)$. Penelitian ini juga menyarankan agar setiap rumah sakit diharapkan membuat standar operasional prosedur untuk IMD dan menyarankan agar dinas kesehatan membuat regulasi yang menwajibkan rumah sakit memberikan fasilitasi bagi ibu yang akan melakukan IMD.

Sedangkan penelitian yang dilakukan oleh Gunnlaugsson G, et.al. (2018) menunjukkan secara crossectional study di Guinea-Bissau menemukan bahwa salah satu faktor yang paling berpengaruh terhadap pelaksanaan IMD adalah peran penolong persalinan dengan OR 3,26 $(1,17-10,2)$. Hal ini menunjukkan bahwa keterampilan penolong persalinan yang membuat mereka memberikan dukungan pada ibu pasca bersalin untuk melaksanakan IMD memegang peranan penting untuk terlaksananya IMD.

Umumnya bayi yang melakukan IMD ini dapat bertahan untuk mengkonsumsi ASI Eksklusif selama 6 bulan. Selain itu dapat pula membantu perekonomian masyarakat karena pemberian ASI Eksklusif selama 6 bulan pertama kelahiran bayi, maka akan menghemat pengeluaran untuk pembelian susu formula. Setidaknya waktu yang dibutuhkan untuk melakukan IMD ini adalah sekitar 60 menit, dan setiap bayi memiliki variasi tersendiri untuk menemukan puting sang ibu.

\section{Dukungan Suami}

Dukungan suami sangat dibutuhkan ibu dalam memilih tenaga penolong persalinan, mendukung atau menyetujui inisiasi menyusu dini (IMD), memotivasi ibu dalam melaksanakan IMD dan suami sadar pentingnya IMD. Ibu yang hidup di tengah keluarganya sangat memerlukan perhatian dan kasih sayang dari keluarganya agar ia tetap hidup sehat yang dimulai sejak dari pemenuhan kebutuhan saat hamil yang lebih banyak dari biasanya dan kebutuhan fisik lainnya sampai pada keputusan dalam memilih penolong persalinan menjelang kelahiran bayinya menunjukkan bahwa responden yang tidak mendapat dukungan dari suami dalam memotivasi ibu untuk melaksanakan IMD cenderung tidak melakukan IMD di wilayah kerja Puskesmas Jumpandang Baru Kecamatan Tallo Kota Makassar 
sebanyak 21 orang $(70,0 \%)$, lebih tinggi dari responden yang mendapat dukungan dari suami hanya 9 orang $(30,0 \%)$. Hasil penelitian menunjukkan bahwa secara proporsional, adanya dukungan dari suami lebih banyak ditemukan pada kelompok yang menerapkan IMD 58,3\% dibandingkan pada yang tidak mendapat dukungan dari suami sebesar $41,7 \%$. Hasil analisis Odds Ratio menunjukkan bahwa ibu dengan adanya dukungan dari suami lebih berpengaruh 3,3 kali lebih besar dalam menerapkan inisiasi menyusu dini (IMD) dari pada yang tidak mendapatkan dukungan dari suami (OR $=3,267 ; 95 \% \mathrm{Cl}: 1,283$ - 8,316) dan secara statistik menunjukkan ada hubungan yang bermakna $(p=0,021)$.

Hasil penelitian ini sejalan dengan (Mularsih dkk. 2011), membuktikan bahwa responden yang mendapatkan dukungan dalam pelaksanaan inisiasi menyusu dini, $77,8 \%$ menyatakan bahwa bayi mereka berhasil melakukan IMD. Hal ini memberikan gambaran bahwa pelaksanaan IMD sangat memerlukan dukungan dari suami ataupun keluarganya dimana dukungan tersebut sangat dibutuhkan oleh ibu menyusui.

Dalam penelitian ini pula didapatkan bahwa beberapa ibu yang mendapat dukungan dari suami tetapi tidak melaksanakan IMD sebanyak 16 ibu $(31,4 \%)$ dikarenakan emosi ibu pasca melahirkan masih belum stabil sehingga rata-rata ibu merasa tidak percaya diri dalam melakukan proses IMD pada bayinya.

Kondisi emosi yang stabil menentukan sikap yang positif dari ibu. Kestabilan emosi tersebut,bisa diraih bila sang suami atau keluarga memberikan dukungan dan motivasinya secara maksimal. Dukungan memberikan suatu kesan bahwa ia dicintai dan diperhatikan, memiliki harga diri dan dihargai. Sehingga dengan sendirinya akan berpengaruh terhadap emosional ibu dimana ia lebih tenang, nyaman, percaya diri dalam melakukan proses IMD pada bayinya. Proses menyusui bayi melibatkan tiga hubungan insani. lbu yang memberikan ASI, si anak yang diberikan dan suami sebagai penyeimbang hubungan. Namun pada kenyataannya, banyak kaum suami maupun keluarganya yang merasa tidak terlibat dalam proses sosial ini dan cenderung menyerahkan segala urusan pemberian ASI pada ibunya saja, serta merasa tidak perlu ikut campur dalam proses ini. Keterlibatan seorang suami dalam pelaksanaan IMD ini akan memberi motivasi ibu untuk menyusui. Jika ibu sudah memiliki motivasi dan optimistis bisa menyusui, air susu pun akan berhamburan (Paramita, 2010).

Hal ini sejalan pula dengan penelitian Suryani dkk (2014) yang menyatakan bahwa ada hubungan yang bermakna antara dukungan suami dengan pelaksanaan IMD $(p=0,000$; $\mathrm{OR}=6,91)$. Hal ini memberikan gambaran bahwa pelaksanaan inisiasi menyusu dini sangat memerlukan dukungan dari suami di mana dukungan tersebut yang paling dibutuhkan oleh ibu menyusui. Hal ini juga sesuai dengan pendapat Roesli (2008) bahwa kondisi emosi menentukan tingkat produksi ASI yang dihasilkan ibu. Kestabilan emosi tersebut bisa diraih bila sang suami turut mendukung.

Pendapat suami amat mempengaruhi seorang wanita untuk mengambil keputusan untuk menyusui bayinya. seorang ibu yang mendapat anjuran dari suaminya untuk menyusui akan secara bermakna menyusui dibandingkan dengan yang mendapat anjuran untuk memberikan susu formula saja pada bayinya. Pemberian dukungan ini bahkan lebih penting dan bermakna disbanding faktor sosiaodemografi. (WorthingtongRoberts. 2010)

\section{KESIMPULAN}

1. Pengetahuan yang cukup mempunyai kemungkinan lebih besar 5,5 kali dibandingkan pengetahuan yang kurang dalam menerapkan inisiasi menyusu dini (IMD).

2. Dukungan dari bidan/penolong persalinan mempunyai kemungkinan lebih besar 12,6 kali dibandingkan yang tidak mendapatkan dukungan dari bidan dalam menerapkan inisiasi menyusu dini (IMD).

3. Dukungan suami mempunyai kemungkinan lebih besar 3,3 kali dibandingkan yang tidak mendapatkan dukungan dari suami dalam 
menerapkan inisiasi menyusu dini (IMD).

4. Hasil uji multivariat menunjukkan bahwa variabel peran bidan/penolong persalinan merupakan faktor yang paling berpengaruh terhadap penerapan inisiasi menyusu dini (IMD) dengan nilai Wald sebesar 13 dan signifikansi sebesar 0,000.

\section{REKOMENDASI}

1. Sebagian ibu yang mempunyai pengetahuan kurang tentang pentingnya proses Inisiasi menyusu dini sehingga informasi tentang pentingnya IMD perlu ditingkatkan misalnya petugas kesehatan bekerja sama dengan instansi kesehatan mengadakan penyuluhan dan konseling agar informasi mengenai Inisiasi menyusu dini dapat terlaksana dan dilaksanakan oleh ibu dengan bimbingan tenaga kesehatan.

2. Pelatihan bagi petugas kesehatan penolong persalinan mengenai tata cara pelaksanaan IMD yang tepat sangat perlu diadakan agar petugas kesehatan yang menolong persalinan dapat menerapkan pelaksanaan IMD dengan tepat kepada ibu pasca bersalin.

3. Mempertahankan kesadaran suami agar senantiasa memberikan dukungan kepada ibu bersalin sejak ibu itu hamil, pendampingan pada saat proses persalinan, sehingga proses pelaksanaan IMD terlaksana dengan baik.

4. Penelitian ini akan ditindaklanjuti berupa Pengabdian Kepada Masyarakat dengan mitra ibu hamil, kader dan Petugas kesehatan, dimana kegiatan ini bertujuan untuk meningkatkan pengetahuan tentang IMD lebih dini sehingga diharapkan semua ibu akan melaksanakan IMD pada saat persalinan.

\section{UCAPAN TERIMA KASIH}

Peneliti mengucapkan terima kasih kepada DIPA Poltekkes yang telah mendukung kegiatan penelitian ini yaitu berupa dana, Poltekkes Makassar dan Unit PPM yang telah memberikan kesempatan berperan serta secara aktif sehingga penelitian dapat terlaksana sesuai waktu yang direncanakan.
DAFTAR PUSTAKA

Ambarwani. 2011. Inisiasi Menyusu Dini dan ASI Eksklusif Membentuk Generasi Rabbani. SUHUF.

Aprillia Y. 2017. Analisis Sosialisasi Program Inisiasi Menyusu Dini dan ASI Eksklusif kepada Bidan di Kabupaten Klaten. Tesis Tidak Diterbitkan. Semarang: Universitas Diponegoro.

Dinas Kesehatan Provinsi Sulawesi Selatan. 2017. Profil Kesehatan Provinsi Sulawesi Selatan Tahun 2017.(online)

(http://www.dinkessulselprov.go.id, diakses 20 November 2018).

Elza, Yussiana. 2018. Dukung lbu Untuk Meraih Emas. (online) (http://www.promosikesehatan.com . diakses pada tanggal19 November 2018).

Fikawati S, Syafiq A. 2010. Kajian Implementasi dan Kebijakan Air Susu Ibu Eksklusif dan Inisiasi Menyusui Dini di Indonesia. Makara Kesehatan ; 14 (1):17-24

Gunnlaugsson G, et.al. 2018. Determinants of delayed initiation of breastfeeding: a community and hospital study from Guinea-Bissau. Int J Epidemiol : 21:935-940.

Hidayat, Karindra A. 2012. Perbandingan Pelaksanaan Inisiasi Menyusu Dini Berdasar Tingkat Pengetahuan lbu Hamil. Tesis Tidak Diterbitkan. Semarang: Universitas Diponegoro.

Mujiati, Novianti. 2015. Pelaksanaan Sosialisasi Inisiasi Menyusu Dini (IMD) di Rumah Sakit St Carolus dan Rumah Sakit Umum Daerah (RSUD) Budhi Asih Jakarta. Buletin Penelitian Kesehatan, Vol. 43, No. 4.

Paramita. 2010. Dukungan Keluarga. [online] http://www.rajawana.com. diakses 17 Juni 2019.

Sheilla Virarisca, Djaswadi Dasuki, Sulchan Sofoewan. 2015. Metode persalinan dan hubungannya dengan inisiasi menyusu dini di RSUP Dr. Sardjito Yogyakarta. Jurnal Gizi Klinik Indonesia 2015, VII (2).

Virarisca S, dkk. 2010. Metode Persalinan dan Hubungannya dengan Inisiasi Menyusu Dini. Jurnal Gizi Klinik Indonesia ;7(2):92-8. 
Tabel 4.1. Distribusi responden berdasarkan kelompok umur di wilayah kerja Puskesmas Puskesmas Jumpandang Baru di Kecamatan Tallo Kota Makassar tahun 2019

\begin{tabular}{ccc}
\hline Umur & $\mathbf{n}$ & $\%$ \\
\hline$<20$ tahun & 7 & 7.8 \\
20-35 Tahun & 71 & 78.9 \\
$>35$ tahun & 12 & 13.3 \\
\hline Total & $\mathbf{9 0}$ & $\mathbf{1 0 0 . 0}$
\end{tabular}

Sumber : Data Primer, 2019

Tabel 4.2. Distribusi responden berdasarkan tingkat pendidikan di wilayah kerja Puskesmas Jumpandang Baru Kecamatan Tallo Kota Makassar

\begin{tabular}{ccc}
\hline Tingkat Pendidikan & $\mathbf{n}$ & $\%$ \\
\hline SD & 21 & 23.3 \\
SMP & 20 & 22.2 \\
SMA & 39 & 43.3 \\
PT & 10 & 11.1 \\
\hline Total & $\mathbf{9 0}$ & $\mathbf{1 0 0 . 0}$
\end{tabular}

Sumber : Data Primer, 2019

Tabel 4.3 . Distribusi responden berdasarkan pekerjaan di wilayah kerja Puskesmas Jumpandang Baru Kecamatan Tallo Kota Makassar

\begin{tabular}{ccc}
\hline Pekerjaan & $\mathbf{n}$ & $\%$ \\
\hline IRT & 88 & 97.8 \\
Pegawai Swasta & 1 & 1.1 \\
PNS & 1 & 1.1 \\
\hline Total & $\mathbf{9 0}$ & $\mathbf{1 0 0 . 0}$ \\
\hline
\end{tabular}

Sumber : Data Primer, 2019

Tabel 4.4. Distribusi responden berdasarkan Paritas di wilayah kerja Puskesmas Jumpandang Baru Kecamatan Tallo Kota Makassar

\begin{tabular}{ccc}
\hline Paritas & $\mathbf{n}$ & $\%$ \\
\hline Primipara & 14 & 15.6 \\
Multipara & 65 & 72.2 \\
Grand Multipara & 11 & 12.2 \\
\hline Total & $\mathbf{9 0}$ & $\mathbf{1 0 0 . 0}$ \\
\hline
\end{tabular}

Sumber : Data Primer, 2019 
Tabel 4.5. Distribusi responden berdasarkan pengetahuan di wilayah kerja Puskesmas Jumpandang Baru Kecamatan Tallo Kota Makassar

\begin{tabular}{ccc}
\hline Pengetahuan & $\mathbf{n}$ & $\%$ \\
\hline Kurang & 42 & 46.7 \\
Cukup & 48 & 53.3 \\
\hline Total & $\mathbf{9 0}$ & $\mathbf{1 0 0 . 0}$ \\
\hline
\end{tabular}

Sumber : Data Primer, 2019

Tabel 4.6. Distribusi responden berdasarkan peran bidan di wilayah kerja Puskesmas Jumpandang Baru Kecamatan Tallo Kota Makassar

\begin{tabular}{ccc}
\hline Peran Bidan & $\mathbf{n}$ & $\%$ \\
\hline Tidak Mendukung & 21 & 23.3 \\
Mendukung & 69 & 76.7 \\
\hline Total & $\mathbf{9 0}$ & $\mathbf{1 0 0 . 0}$ \\
\hline
\end{tabular}

Sumber : Data Primer, 2019

Tabel 4.7. Distribusi responden berdasarkan Dukungan Suami di wilayah kerja Puskesmas Jumpandang Baru Kecamatan Tallo Kota Makassar

\begin{tabular}{ccc}
\hline Dukungan Suami & $\mathbf{n}$ & $\%$ \\
\hline Tidak Mendukung & 46 & 51.1 \\
Mendukung & 44 & 48.9 \\
\hline Total & $\mathbf{9 0}$ & $\mathbf{1 0 0 . 0}$ \\
\hline
\end{tabular}

Sumber : Data Primer, 2019

Tabel 4.8. Distribusi responden berdasarkan Penerapan IMD di wilayah kerja Puskesmas Jumpandang Baru Kecamatan Tallo Kota Makassar

\begin{tabular}{ccc}
\hline Penerapan IMD & $\mathbf{n}$ & $\%$ \\
\hline Tidak Melakukan IMD & 30 & 33.3 \\
Melakukan IMD & 60 & 66.7 \\
\hline Total & $\mathbf{9 0}$ & $\mathbf{1 0 0 . 0}$ \\
\hline
\end{tabular}

Sumber : Data Primer, 2019

Tabel 4.9. Pengaruh pengetahuan terhadap penerapan inisiasi menyusu dini di wilayah kerja Puskesmas Jumpandang Baru Kecamatan Tallo Kota Makassar

\begin{tabular}{|c|c|c|c|c|c|c|c|}
\hline \multirow{3}{*}{ Pengetahuan } & \multicolumn{4}{|c|}{ Penerapan IMD } & \multirow{3}{*}{ Total } & \multirow{3}{*}{$\%$} & \multirow{3}{*}{$\begin{array}{c}\text { OR } \\
\text { LL - UL } \\
P \text { value }\end{array}$} \\
\hline & \multicolumn{2}{|c|}{$\begin{array}{c}\text { Tidak } \\
\text { Melakukan } \\
\text { IMD } \\
\end{array}$} & \multicolumn{2}{|c|}{$\begin{array}{l}\text { Melakukan } \\
\text { IMD }\end{array}$} & & & \\
\hline & $n$ & $\%$ & $\mathrm{n}$ & $\%$ & & & \\
\hline Kurang & 22 & 73,3 & 20 & 33,3 & 42 & 46,7 & 5,500 \\
\hline Cukup & 8 & 26,7 & 40 & 66,7 & 48 & 53,3 & 2,083 \\
\hline Total & 30 & 100 & 60 & 100 & 90 & 100 & 0,001 \\
\hline
\end{tabular}

Sumber : Data Primer, 2019

Vol. XV No. 2, Desember 2020 
Tabel 4.10. Pengaruh peran bidan/ penolong persalinan terhadap penerapan inisiasi menyusu dini di wilayah kerja Puskesmas Jumpandang Baru Kecamatan Tallo Kota Makassar

\begin{tabular}{|c|c|c|c|c|c|c|c|}
\hline \multirow{3}{*}{$\begin{array}{l}\text { Peran Bidan/ } \\
\text { Penolong } \\
\text { Persalinan }\end{array}$} & \multicolumn{4}{|c|}{ Penerapan IMD } & \multirow{3}{*}{ Total } & \multirow{3}{*}{$\%$} & \multirow{3}{*}{$\begin{array}{l}\text { OR } \\
\text { LL - UL } \\
\text { P value }\end{array}$} \\
\hline & \multicolumn{2}{|c|}{$\begin{array}{c}\text { Tidak } \\
\text { Melakukan } \\
\text { IMD } \\
\end{array}$} & \multicolumn{2}{|c|}{$\begin{array}{l}\text { Melakukan } \\
\text { IMD }\end{array}$} & & & \\
\hline & $\mathrm{n}$ & $\%$ & $\mathrm{n}$ & $\%$ & & & \\
\hline $\begin{array}{c}\text { Tidak } \\
\text { Mendukung }\end{array}$ & 16 & 53,3 & 5 & 8,3 & 21 & 23,3 & $\begin{array}{c}12,571 \\
3929-40223\end{array}$ \\
\hline Mendukung & 14 & 46,7 & 55 & 91,7 & 69 & 76,7 & \\
\hline Total & 30 & 100 & 60 & 100 & 90 & 100 & 0,000 \\
\hline
\end{tabular}

Sumber : Data Primer, 2019

Tabel 4.11. Pengaruh dukungan suami terhadap penerapan inisiasi menyusu dini di wilayah kerja Puskesmas Jumpandang Baru Kecamatan Tallo Kota Makassar

\begin{tabular}{|c|c|c|c|c|c|c|c|}
\hline \multirow{3}{*}{$\begin{array}{l}\text { Dukungan } \\
\text { Suami }\end{array}$} & \multicolumn{4}{|c|}{ Penerapan IMD } & \multirow{3}{*}{ Total } & \multirow{3}{*}{$\%$} & \multirow{3}{*}{$\begin{array}{c}\text { OR } \\
\text { LL - UL } \\
\text { P value }\end{array}$} \\
\hline & \multicolumn{2}{|c|}{$\begin{array}{c}\text { Tidak } \\
\text { Melakukan } \\
\text { IMD } \\
\end{array}$} & \multicolumn{2}{|c|}{$\begin{array}{l}\text { Melakukan } \\
\text { IMD }\end{array}$} & & & \\
\hline & $\mathrm{n}$ & $\%$ & $\mathrm{n}$ & $\%$ & & & \\
\hline $\begin{array}{c}\text { Tidak } \\
\text { Mendukung }\end{array}$ & 21 & 70,0 & 25 & 41,7 & 46 & 51,1 & 3,267 \\
\hline Mendukung & 9 & 30,0 & 35 & 58,3 & 44 & 48,9 & \\
\hline Total & 30 & 100 & 60 & 100 & 90 & 100 & 0,021 \\
\hline
\end{tabular}

Sumber : Data Primer, 2019

Tabel 4.12. Hasil uji Bivariat masing-masing variabel independen yang diikutkan dalam Analisis Multivariat

\begin{tabular}{lcl}
\hline \multicolumn{1}{c}{ Variabel Independen } & Significant $(\mathrm{p})$ & Diikutkan \\
\hline Pengetahuan Responden & 0,001 & Diikutkan \\
Peran Bidan/Penolong Persalinan & 0,000 & Diikutkan \\
Dukungan Suami & 0,021 & Diikutkan \\
\hline
\end{tabular}

Sumber : Data Primer , 2019

Tabel 4.13 Hasil Analisis Variabel in the equation Regresi Berganda Logistik Faktor Pengaruh penerapan Inisiasi Menyusu Dini (IMD) di wilayah kerja Puskesmas Jumpandang Baru Kecamatan Tallo Kota Makassar

\begin{tabular}{lcccccc}
\hline \multirow{2}{*}{ Variabel Penelitian } & B & \multirow{2}{*}{ Exp (B) } & \multirow{2}{*}{ Wald } & LL & UL & p \\
\hline $\begin{array}{l}\text { Pengetahuan } \\
\text { Responden }\end{array}$ & 1,313 & 3,716 & 5,796 & 1,276 & 10,816 & 0,016 \\
$\begin{array}{l}\text { Peran Bidan/Penolong } \\
\text { Persalinan }\end{array}$ & 2,222 & 9,228 & 12,956 & 2,752 & 30,948 & 0,000 \\
\hline Const. & $-1,552$ & 0,212 & 7,561 & & & 0,006 \\
\hline
\end{tabular}

Sumber : Data Primer , 2019 